\title{
Programmable protective device for LV distribution system protection
}

\author{
S. Gopiya Naik*, Vibin Ravi and Ramya Arshiya
}

\begin{abstract}
High quality electric power supply is the prime goal in the modern power systems around the world. One of the main ways to achieve this is the protection of the system which needs to be fast, reliable and cost effective. The objective of this paper is to provide protection of equipments in low voltage (LV) distribution system and thereafter to avoid their failure due to abnormal operating conditions. The proposed device provides protection for industrial, commercial and residential equipments by monitoring under voltage, over voltage and over current conditions using microcontroller, transistor and other discrete components. The microcontroller is the heart of this protective device which performs the major control of the device. The designed circuit can withstand the loads and the set voltage range so as to supply the connected load for any voltage variation between 220 and 240 Volts. It can be used to protect loads such as refrigerator, TV, VCR/DVD player etc. against undesirable over and under voltage conditions as well as surges caused due to sudden failure of power supply mains. This device can also be used directly as standalone equipment between the supply mains and the load. The over/under voltage and over current cut-off with time delay provides over/under-voltage and over current protection and also protection against any transients.
\end{abstract}

Keywords: Distribution system, Protective device, Microcontroller, Over -under voltage, Over current

\section{Introduction}

The purpose of the electrical power distribution system is to supply good quality, safe and reliable power to the consumers, load centres, industrial plants, etc. Now-a-days high quality power is basic need of highly automated industries and home appliances ([1], https://en.wikipedia.org/wiki/ Automation). The quality and security of power system are disturbed due to faults and failures occurring. Protection against sudden over voltages in substations is a vital part of the overall reliability of power systems $[2,3]$. The protection against over voltage is mainly necessary for human being because the people will lose their life due to overvoltage shock. The degree of surge protection provided to a station is governed by the reliability requirement and the economics to obtain such reliability. Since major stations generally include strategic and highly valuable power equipment, surge protection is essential to avoid or minimize major system disturbances as well as major equipment failures. Transient over voltages occurring in

\footnotetext{
* Correspondence: gopiya_s@yahoo.co.in

Department of Electrical and Electronics Engineering, PES College of Engineering, Mandya, Karnataka, India
}

the power systems can cause operational breakdown and also cause failure in industrial and household equipments as well.

Voltage irregularities are one of the greatest power quality issue faced by industry and domestic appliances is responsible for damaging valuable electrical equipments. Electrical Power System protection is required for protection of both user and the system equipment from faults; hence electrical appliances are not allowed to operate without any protective device installed. Power System fault is defined as undesirable condition that occurs in the power system like short circuit, current leakage, ground short, over current, under and over voltage, etc.

The ability of protection system is demanded not only for economic reason but for expert and reliable service. Technically speaking, an over/under voltage and over current condition is reached when the voltage exceeds or lags the nominal voltage and current exceeds the normal rated current, respectively. Under voltage might result into burn out, distortion or permanent damage while over voltage in the form of spikes and surges could cause 
distortion, burn-out, meltdown and fire, electro-pulsing and permanent damage. Owing to the incessant damages done by fluctuations in the power supply, there is urgent need to address the problem through other alternatives, which give birth to design and construction of an equipment to protect the connected loads against under and/ over voltage and over current conditions. Under/over voltage and over current protection is essential between supply terminal and the appliances (connected loads).

Actually sudden fluctuation in the voltage is very high and causes serious problems in industries and home appliances and it also causes power loss in the electrical circuits. These losses cause low power factor in the supply and due to this much amount of power is going to be wasted. Further, these fluctuations may significantly impact the power quality as well as the reliability of other voltage controlling devices and various costly and precious equipments may get damaged.

When the RMS voltage or current drops between 0.1 and $0.9 \mathrm{pu}$ at power frequency for duration of 0.5 cycles to $1 \mathrm{~min}$, then it is said to be sag condition. The swell condition will occur when RMS voltage or current rises between 1.1 and $1.8 \mathrm{pu}$ at power frequency for the duration of 0.5 to $1 \mathrm{~min}$, and above $1.8 \mathrm{pu}$ and below 0.9 $\mathrm{pu}$ is called over voltage and under voltage conditions, respectively [4]. Voltage sags and under voltage conditions are caused by abrupt increase in loads due to short circuit and faults or it is caused by abrupt increase in source impendence caused by loose connection. Voltage swell and over voltage conditions are always caused by an abrupt decrease in load on a circuit with a poor or damaged voltage regulator, although they can also be caused by a damaged or loose neutral connection.

Majority of the papers available in literature on LV distribution system protection considers only over or under voltage or over current protection or over and under voltage protection. But the method proposed in this paper considers all in together. The aim of this work is to develop a protective system that monitors the abnormal conditions that taking place in LV distribution systems and provide breakpoint based on low/ high voltage and over current tripping mechanism; that avoids any damage to the load, various industrial and domestic appliances consisting of fluctuation in the AC mains. The proposed protection device is capable to protect domestic equipments like: refrigerator, induction motor (IM) and other electrical appliances from abnormal conditions.

\section{Methods}

The methodology proposed in this work consists of development of block diagram of the protective device, background to the most commonly arising problems in the power system network and a brief discussion about the micro controller used in this work.

\subsection{Functional block diagram of proposed protection scheme}

The aim of the proposed work is to develop a system that monitors the voltage variation and provides breakpoint based on low and high voltage tripping mechanism that avoids any damage to the load, various industrial and domestic systems consisting of fluctuation in the AC mains. In the tripping mechanism shown in Fig. 1, a quad comparator IC is used with two more comparator ICs as window comparator. When the system delivers error, the input voltage falls out of the window range. This trigger then operates a relay that cut off the lamp load to avoid any damage. So the high quality power can be obtained with the help of this device and it will also improve the power factor and thus power can be fully utilized. The proposed protection circuit protects

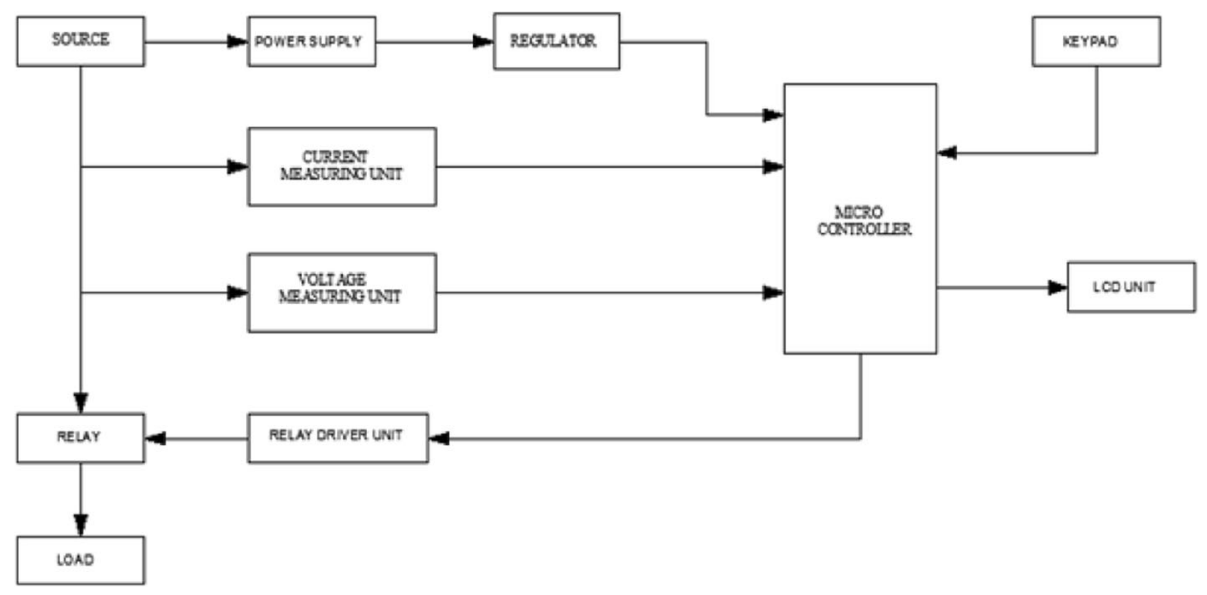

Fig. 1 Block diagram of a proposed protection scheme 
refrigerator, IM and other electrical appliances from abnormal conditions.

\subsection{Over voltage}

When the voltage in a circuit or part of it is raised above its upper design limit, this is known as over voltage [5]. The conditions may be hazardous. Depending on its duration, the over voltage event can be transient (a voltage spike as shown in Fig. 2) or permanent, leading to a power surge. Over voltages are less common than under voltage but they also arise due to system faults. Overvoltage can occur due to single line to ground fault, which in turn will raise the voltage of the other phases. It can also happen due to disconnection of heavy industrial loads or switching on the capacitor banks or energization of capacitor bank. This is generally due to ungrounded or floating ground delta systems, where a change in ground reference would give voltage rise to the ungrounded system. It can also be generated by sudden load deduction. Due to the disconnection of load there is a sudden reduction of current, which will gives rise to over voltage, where L is the inductance of the line. The effects of over voltage are more severe and destructive. It may cause the electrical equipment to fail, due to overheating caused by high voltage. Also electronic and other sensitive equipment are prone to malfunction.

\subsection{Under voltage}

Under voltage is defined as a sudden drop in the root mean square (r.m.s.) voltage and is usually characterized by the remaining (retained) voltage [5]. Under voltage is thus, short duration reduction in r.m.s. voltage, caused mainly by short circuit, starting of large motors and equipment failure. Under voltages are the most common power disturbance whose effect is quite severe especially in industrial and large commercial customers such as the damage of the sensitivity equipments and loss of daily productions and finances. The examples of the sensitive equipments are Programmable Logic Controller (PLC),

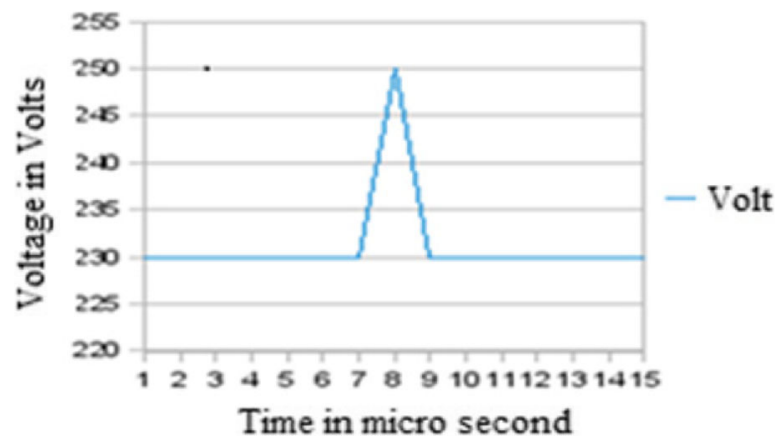

Fig. 2 Voltage Spike
Adjustable Speed Drive (ASD) and Chiller control. Under voltage at the equipment terminal can be due to a short circuit fault hundreds of kilometers away in the transmission system.

\subsection{Over current}

In an electric power system, over current or excess current is a situation where the value larger than intended electric current exists through a conductor, leading to excessive generation of heat which leads to the risk of fire or damage to equipment [5-7]. Possible causes for over current include short circuit, excessive load, incorrect design, or a ground fault. Fuses, circuit breakers, temperature sensors and current limiters are commonly used protection mechanisms to control the risks of over current. Over current protection also includes the protection against over loads and this is most widely used protection. Over loading of a machine (or equipment) means the machine is taking more current than its rated current. Hence, with overloading there is an associated temperature rise. The permissible temperature rise has a limit based on insulation class and material. Over current protection against overload is generally provided by thermal relays. Over current protection also includes protection against short-circuit. Short circuits may leads to phase faults, earth faults or winding faults. Short circuit currents are generally several times more than full load current. Hence fast fault clearance is always desirable at the time of short-circuits.

\subsection{Microcontroller}

The microcontroller [8-10] is a small, low cost, on-chip computer. It essentially includes:

- An 8 or 16 bit microprocessor as central processing unit (CPU).

- A small amount of RAM.

- Programmable ROM and/or flash memory.

- Parallel and/or serial I/O.

- Timers and signal generators.

- Analog to Digital (A/D) and/or Digital to Analog (D/A) conversion.

- Often used to run dedicated code that controls one or more tasks in the operation of a device or a system.

- Also known as embedded controller because the microcontroller and supporting circuits are often built into, or embedded in, the devices they control.

- Devices that utilize microcontrollers include car engines, consumer electronics (VCRs, microwaves, cameras, pagers, cell phones), computer peripherals (keyboards, printers, and modems), test/ measurement equipment (signal generators, multimeters, and oscilloscopes). 
- Microcontrollers usually must have low-power requirements $(\sim 0.05-1 \mathrm{~W}$ compared to $\sim 10-50 \mathrm{~W}$ of general purpose desktop CPUs) since many devices they control are battery operated.

The microcontroller performs the major functions of decision and control. The input supply voltage is fed to the microcontroller via current measuring unit and voltage measuring unit. The microcontroller was used in this circuit in order to reduce the complexity of the design and to ensure an easy interface with a liquid crystal display (LCD).

\section{Development of the proposed methodology}

This section deals with description of flow chart, working of the proposed protective device and result discussion.

\subsection{Description of flow chart}

The execution flow begins with start (Fig. 3). From start, the signal flows to the peripheral initialization. In the peripheral initialization the ports of following devices are initialized:

- RELAY.

- LCD

In LCD there are four modes of operation. They are:

Mode 1: The mode 1 operation is the default operation. Mode 2: This mode is used for selections of over voltage. In this mode the desired value of over voltage is selected.

Mode 3: This mode is used for selections of low voltage. In this mode the desired value of low voltage is selected.

Mode 4: This mode is used for selections of over current. In this mode the desired value of over current is selected.

\subsection{Main voltage monitoring}

The signal from the peripheral initialization is fed to this module. The required operating voltage for monitoring is $120 \mathrm{~V}$. If the voltage is less than $120 \mathrm{~V}$ the power will flows to the power off module and then to supply monitor and after monitoring, the signal flows to the start. If the voltage is above $120 \mathrm{~V}$, the supply will be fed to the current and voltage calculation module followed by the main voltage monitoring. In the current and voltage calculation module the under voltage, over voltage and over current parameters are adjusted according to the applications required and the signal is fed to voltage and current set parameter module. In this module the reference voltage is adjusted according to the requirement. When the voltage and current exceeds or lesser than the refe rence value, it gives signal to the relay driver circuit in which the relay in normally closed condition becomes normally open condition. Otherwise, if the voltage or current value is equal to reference value the relay will be in normally closed condition. For every $10 \mathrm{~s}$ the signals from relay driver circuit is fed to the current or voltage calculation module for continuous operation.

\subsection{Working}

The proposed protection scheme which provides protection to the circuit against the common problem of power system analysis like: under voltage, over voltage and over current is as shown in Fig. 1. Single phase supply is considered and protection is provided against the abnormalities those taking place in single phase system.

Normal working voltage for the single phase AC system is $220 \mathrm{~V}$ and + or $-10 \%$ tolerance is considered. This supply is converted into DC with the help of AC- DC converter followed by the RLC filter. The filter circuit removes the ripples which present in the DC. The output of the filter is DC and this is given as input to the regulator, where the voltage can be varied up to $440 \mathrm{~V}$. The

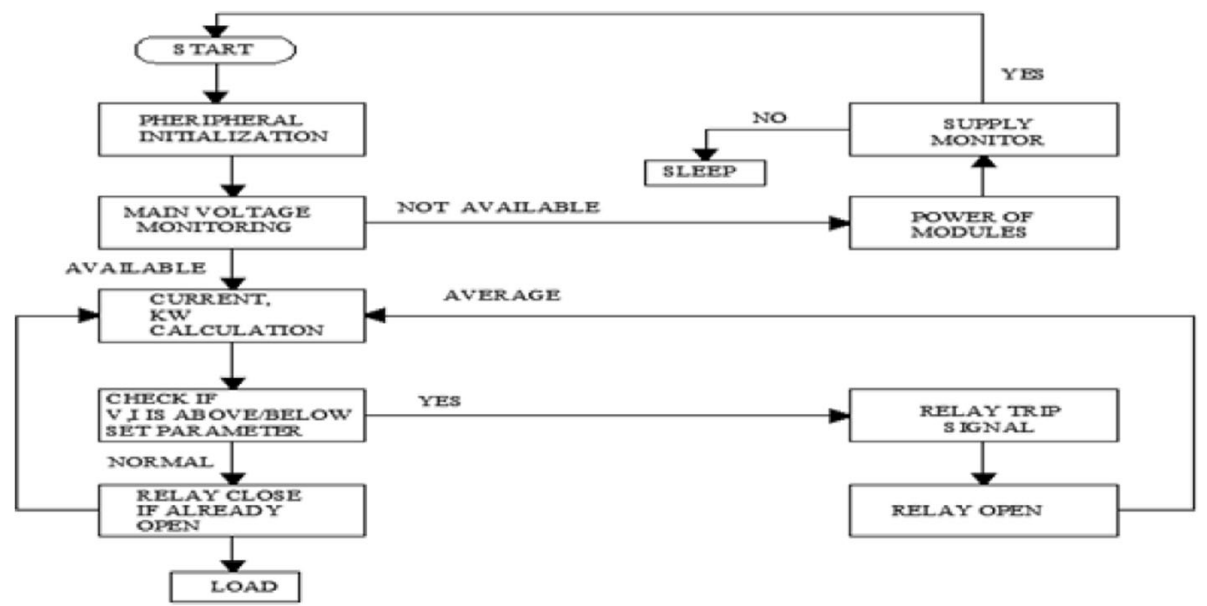

Fig. 3 Flow Chart of the proposed work 
regulator provides constant supply required for the microcontroller and relay system even though there is any changes that has happens in the input side of regulator. The normal supply obtained at the output side of regulator is $12 \mathrm{~V}$. When over current fault occurs the current transformer connected to the supply side converts that high value of current into low value and supply it to the microcontroller through analog to digital converter (ADC). In case when over voltage condition occurs the high values of voltage is reduced to low value of voltage and send that signal to ADC. The ADC converts analog signal into digital signal which is understood by the microcontroller.

The reference value of voltage and current are fed by software ([11] https://www.nxp.com/docs/en/data-sheet/ 8XC51_8XC52.pdf, http://www.datasheetcatalog.org/datasheet/maxim/MAX232.pdf, http://www.enwikipedia.org/ wiki/GSM., www.aimglobal.org/technologies/rfid/what_is_r fid.asp, http://www.alldatasheet.com, http://www.nkelectronics.com, http://www.microelectronics.com) to the microcontroller. The reference voltage that was set in the micro controller is compared with the signal from current and voltage transformers. If it is greater or lesser than the reference voltage or current it gives signal to the relay driver circuit to trip the relay. The LCD is used to display the values of current and voltage. The keypads are used to set the reference voltage and current as per standard. So, the problems occurred due to sag, swell, over / under voltage and over current conditions can be detected and protected by the device.

\section{Results}

In this work implementation of a protective circuit is done which helps to detect the voltage below $198 \mathrm{~V}$ (which is 0.9 times the rated voltage of $220 \mathrm{~V}$ ) and it is a sag and under voltage condition) and above $242 \mathrm{~V}$ it is over voltage and swell condition. During under voltage condition, the proposed circuit will remain in open condition so there will not be any passage of current. In this condition lower relay of the circuit will remain open.

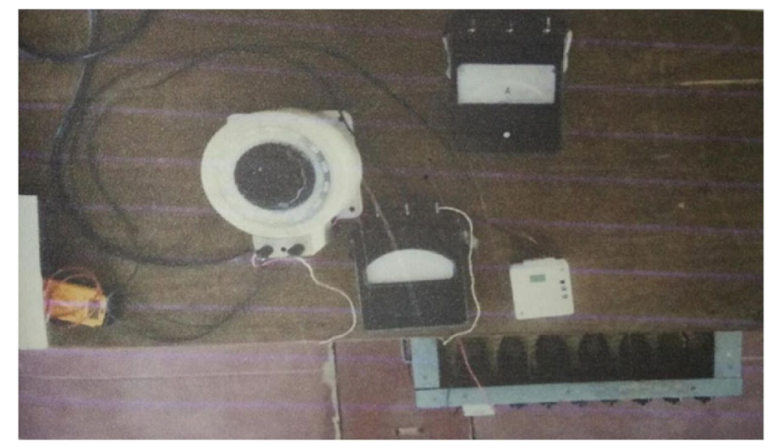

Fig. 4 Practical setup for testing the performance of a protective device

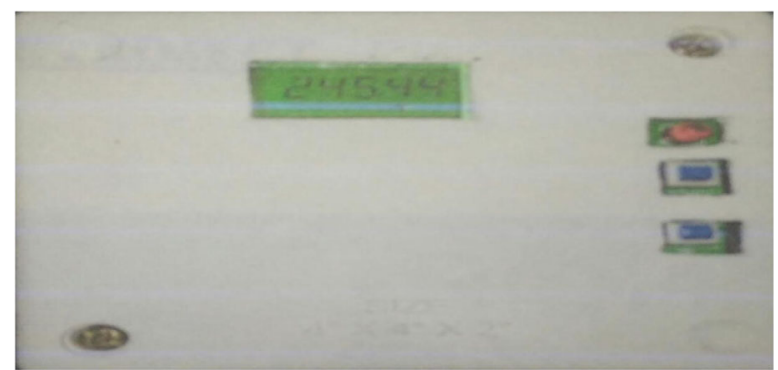

Fig. 5 Programmable protective device indicating over voltage condition

When the voltage rises above $242 \mathrm{~V}$ (which is 1.1 times the rated voltage of $220 \mathrm{~V}$ and it is a swell and over voltage condition). Under this situation the circuit will remain open because during that time the upper relay in the circuit will remain open. Thus we can protect the costly equipment's by disconnecting the supply to the circuit during abnormal conditions.

\section{Discussion}

Figure 4 shows the practical setup for testing the performance of the proposed protective device. This setup includes a single phase auto transformer (dimmerstat), $\mathrm{AC}$ ammeter $(0-10) \mathrm{A}, \mathrm{AC}$ voltmeter $(0-300) \mathrm{V}$, the developed protective device module and a lamp load. In case when the voltage raises above $242 \mathrm{~V}$, the over voltage relay equipped within the module will trip and the circuit is disconnected and the over voltage value is displayed by the LCD device as shown in Fig. 5. When the voltage falls below $198 \mathrm{~V}$ the under voltage relay equipped within the module will trip disconnecting the circuit and under voltage value is displayed by the LCD device as shown in Fig. 6. Further, when the load current goes beyond the normal rated value the over current relay equipped within the module will trip and over current value is displayed by the LCD device as shown in Fig. 7.

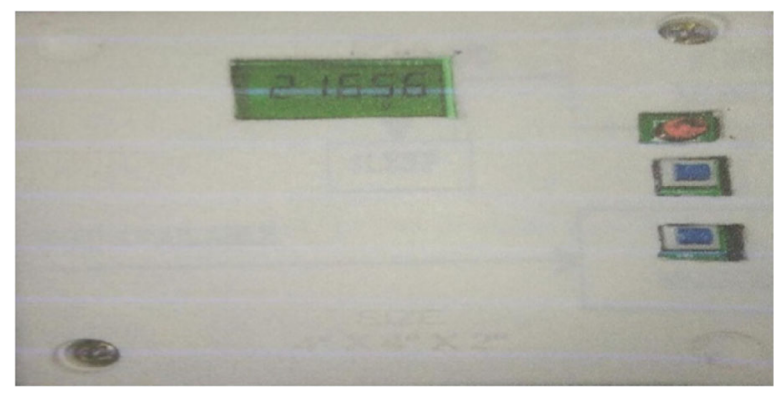

Fig. 6 Programmable protective device indicating under voltage condition 


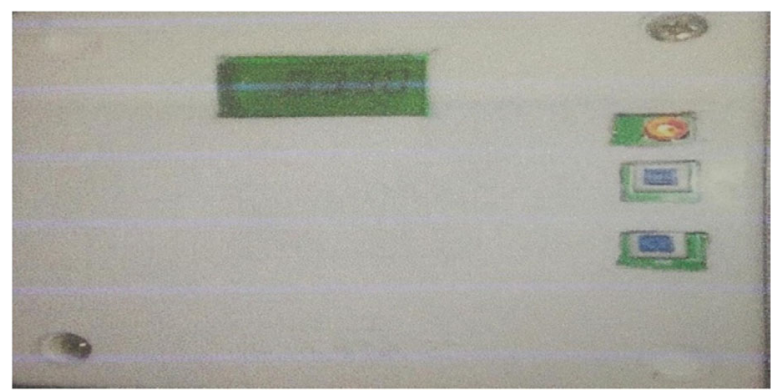

Fig. 7 Programmable protective device indicating over current condition

\section{Conclusions}

The protection circuit proposed in this paper can be used to protect the costly electrical appliances from abnormal conditions like sag, swell, under voltage, over voltage, over current and able to avoid appliances being get damaged from harmful effects. The advantages of this protective device are: highly sensitive, fit and forget system, low cost and reliable circuit, complete elimination of manpower, can handle heavy loads up to 7A, auto switch OFF during abnormal conditions and auto switch $\mathrm{ON}$ at the time of normal conditions. The applications of this protection device are in industrial machinery, house hold appliances like: TV, refrigerator, air conditioner, agriculture motors, and water pumps. This device can also be used directly as standalone equipment between the supply mains and the load. The over/under voltage and over current cut-off with time delay provides over/under-voltage and over current protection and also protection against any transients. If tap changing transformer is used and is automatically controlled, then the device can operate the load normally during under voltage and over voltage condition. Hence, we can protect as well as operate the load in abnormal conditions also. The proposed system can be further improved by integrating it with GSM modem that alerts user by sending an SMS about the tripping status.

\section{Acknowledgements}

The authors would like to express the deepest thanks to the principal, PESCE, Mandya, and the Management, PET ${ }^{\oplus}$, Mandya, for their timely support and constant encouragement in successful completion of this research work.

\section{Funding}

TEQIP fund PESCE. Mandya.

Availability of data and materials

Data sharing not applicable to this article.

\section{About the authors}

S. Gopiya Naik(1968-), male, PHD and Associate Professor, Major in the planning of distribution system, renewable energy sources.

\section{Authors' contributions}

GNS identified the problem and monitored the whole research work, VR formulated the methodology and RA together with VR implemented, designed and tested the proposed scheme and ensured the results successively. All authors read and approved the final manuscript.

\section{Competing interests}

The authors declare that they have no competing interests.

Received: 26 October 2017 Accepted: 16 August 2018

Published online: 14 September 2018

\section{References}

1. Lucas, J.R. (2005). Power system analysis; faults, EE423.

2. Butto, G. M., Jensen, B. B., et al. (2013). Protection of low voltage CIGRE distribution network. Smart grid and renewable energy (Vol. 4, pp. 489-500).

3. Manish, P., Antara, C., \& Snigdha, S. (2015). Hardware implementation of over voltage and under voltage protection. International journal of innovative research in electrical, electronics. Instrum Control Eng, 3(6), 140-144.

4. IEEE Recommended practice for monitoring electric power quality. (1995). IEEE Std. In 1159-1995.

5. Vithalani, C.H. (2017). Over-under voltage protection of electrical appliances. Electronics for You.Com, March 1.

6. Eur Ing, G.S., Eur Ing, J.B. (2009). A practical guide to wiring regulations. (Ch.7), $4^{\text {th }}$ edition, Wiley online library.

7. From Wikipedia, the free encyclopedia.

8. Lee, C. V. (1995). Mobile cellular telecommunications analog and digital systems (2nd ed.). Lisbon: Mc-Graw Hill.

9. Gibson, J. D. (1999). The mobile communication handbook (2nd ed.). USA: CRC Press Ltd..

10. Spacor, P. (1993). Microcontroller technology. USA: Prentice Hall.

11. Michael, B. Embedded C coding standard.

\section{Submit your manuscript to a SpringerOpen ${ }^{\circ}$ journal and benefit from:}

- Convenient online submission

- Rigorous peer review

- Open access: articles freely available online

- High visibility within the field

- Retaining the copyright to your article

Submit your next manuscript at $\boldsymbol{\nabla}$ springeropen.com 